\title{
Assessing the efficiencies and challenges for nutrient uptake by aquatic plants
}

\section{Angove, Charlotte}

2018-10

Angove , C , Norkko , A \& Gustafsson , C 2018 , ' Assessing the efficiencies and challenges for nutrient uptake by aquatic plants ' , Journal of Experimental Marine Biology and Ecology , vol. 507 , pp. 23-30 . https://doi.org/10.1016/j.jembe.2018.07.005

http://hdl.handle.net/10138/308898

https://doi.org/10.1016/j.jembe.2018.07.005

cc_by

acceptedVersion

Downloaded from Helda, University of Helsinki institutional repository.

This is an electronic reprint of the original article.

This reprint may differ from the original in pagination and typographic detail.

Please cite the original version. 
1 This is the AUTHORS' ACCEPTED MANUSCRIPT, for the published article, please see:

2 https://doi.org/10.1016/j.jembe.2018.07.005

3 Full citation: ANGOVE, C., NORKKO, A. and GUSTAFSSON, C., 2018. Assessing the

4 efficiencies and challenges for nutrient uptake by aquatic plants. Journal of Experimental

5 Marine Biology and Ecology, 507, pp. 23-30.

6

7 Assessing the efficiencies and challenges for nutrient uptake by aquatic plants

9 Charlotte Angove, Alf Norkko, Camilla Gustafsson

11 Charlotte Angove (corresponding author), Tvärminne Zoological Station, University of

12 Helsinki, J.A. Palménin tie 260, 10900 Hanko, Finland

13 charlotte.angove@helsinki.fi, phone: +358-406433609

14 Alf Norkko, Tvärminne Zoological Station, University of Helsinki, J.A. Palménin tie 260, 1510900 Hanko, Finland

16 Baltic Sea Centre, Stockholm University, SE-106 91, Stockholm, Sweden

17 Camilla Gustafsson, Tvärminne Zoological Station, University of Helsinki, FIN-10900

18 Hanko, Finland

19 
Aquatic plant meadows are valuable components to the 'coastal filter' and it is important to understand the processes that drive their ability to cycle nutrients. However, at present, the field-based evidence for understanding the drivers of nutrient uptake by plants is lacking. This study aimed to investigate how well individual shoots of aquatic plants could meet their nitrogen demands using the sediment nutrient pool (porewater ammonium) and to explore which traits helped to facilitate such uptake. Several species were investigated in shallow, submerged (2-4 m) mixed-species communities in the northern Baltic Sea using incubation experiments with enriched ammonium. After a $3.5 \mathrm{~h}$ incubation time, individuals were collected and analysed for nitrogen (\% DW) and ${ }^{15} \mathrm{~N}$ (at-\%) concentrations. Uptake by plants was calculated per unit nitrogen in response to the ${ }^{15} \mathrm{~N}$-labelled source and to overall nitrogen availability. Background porewater ammonium availability was highly variable between individual plants. Species identity did not significantly affect uptake metrics and the effect of ambient porewater availability was weak. As biomass increased there were significant logarithmic declines in the $95^{\text {th }}$ quantiles of nutrient uptake rates, ambient porewater nutrient availability and aboveground nitrogen tissue concentrations (\% DW). Such findings suggested that uptake rates of plants were significantly demand-driven and the nutrient conditions of the porewater were significantly driven by the demands of the plant Findings parameterised the unfulfilled potential for some aquatic plants to cycle nutrients more efficiently and highlighted the potential importance of access to new nutrient sources as a way of enhancing nutrient cycling by aquatic plants. Plant traits and community properties such as the activity of infauna could facilitate such an access and are likely important for nutrient uptake. 
45 Keywords: Nitrogen, functional traits, seagrass, Baltic Sea, sediment, Zostera marina, nutrient cycling, nutrient enrichment.

Running page head: Nitrogen uptake by aquatic plants

\section{Introduction}

Aquatic plant meadows are valuable for cycling nutrients in coastal zones (McGlathery et al., 2007). They absorb dissolved nutrients and store them as biomass, which is then available for further processes such as burial or grazing by consumers, and it ultimately slows the rerelease of inorganic nutrients into the surrounding environment (McGlathery et al., 2007). Understanding uptake processes is particularly important in the Baltic Sea because many of its ecosystems are threatened by eutrophication (see Andersen et al., 2009; Gustafsson et al., 2012) which has been accelerated by an increase in nutrient concentrations from anthropogenic nutrient loading to coastal zones (Gustafsson et al., 2012). It is hence imperative to investigate how well aquatic plants can access and utilise nutrient pools in the surrounding environment and understand what enhances their ability to cycle nutrients.

Aquatic plants absorb dissolved organic and inorganic nutrients from the water column and, mainly, the sediment porewater (Erftemeijer and Middelburg, 1995; Touchette and Burkholder, 2000). Nutrient availability in the sediment is increased by processes such as excretion by fauna (Peterson and Heck, 2001; Peterson and Heck, 1999) as well as the decomposition of organic matter (Kenworthy and Thayer, 1984), including vegetation and fauna, phytodetritus (Evrard et al., 2005) and other particles entrained from the water column (Kennedy et al., 2010). Such factors are highly spatiotemporally variable (e.g. Hemminga, 1998; Wirachwong and Holmer, 2010; Fourqurean et al., 1992). Nutrients can be depleted to the extent that aquatic plant growth is nutrient-limited (Perez et al., 1991; Ferdie and Fourqurean, 2004; Armitage et al., 2011); which is not always the case (as observed by Olsen 
and Valiela, 2010; Mutchler and Hoffman, 2017; Campbell and Fourqurean, 2014), but nutrient availability can drive spatial differences in plant patch development (Furman et al., 2017). Such a large-scale response to nutrient availability is owing to the responsive foraging and growth strategies by roots and clonal ramets to nutrient availability (Furman et al., 2017; Kembel et al., 2008; Campbell et al., 1991; de Kroon and Mommer, 2006). Thus, nutrient variability is highly influential to the development of aquatic plant meadows and their ability to cycle nutrients.

If an individual plant had a greater capacity to meet its nutrient demands using the resources that were available (e.g. Comas and Eissenstat, 2004), it would cycle nutrients more efficiently in the place that it grows, be more robust to temporal change in nutrient availability and in turn the meadow structure would be more robust to changes in nutrient availability. The growth of the root network of a plant is coordinated by its hormonal cues in response to nutrient demands. In terrestrial environments, the growth responses and root architectural strategies to meet nutrient demands change between species (Kembel et al., 2008; Campbell et al., 1991). These strategies can enhance uptake to different levels of success depending on the environment. For instance, having a higher root length per unit root mass (Specific Root Length, SRL) reduces the distance that nutrients must diffuse to reach the roots, and this benefits plants in nutrient poor environments because it catalyses nutrient supply (Aerts, 1999). However, in nutrient-rich zones the nutrient supply is no longer the limiting factor; instead it is the rate at which plants can absorb the available nutrients and so their physiological nutrient uptake kinetics become more important for enhancing nutrient uptake (Aerts, 1999). In the context of aquatic plant communities, we do not know which strategies are valuable for uptake and thus, what the nutrient microenvironment is like for an individual plant. While the physiology of different aquatic plant species can vary (e.g. Gustafsson and Norkko, 2016), coarser-scale morphological variations which affect uptake 
rates are still yet to be explored. For instance, seagrasses and other aquatic plants often develop a network of ramets which can share nutrients (Marbà et al., 2002); a strategy which enhances nutrient uptake in terrestrial environments with heterogeneous nutrient availability (Roiloa and Hutchings, 2013). Yet for any single shoot in natural conditions, we do not understand which conditions are most important for uptake success. For seagrass, root traits are likely to represent extremely poor nutrient conditions because the spatiotemporal variability of nutrients can be so influential on meadow growth (Furman et al., 2017) that the variability of traits which enhance uptake kinetics are likely to be redundant compared to the ability for plants to increase their reach to access new nutrient sources. In this case, growing longer roots would likely be the most important attribute for nutrient uptake rather than the amount of absorptive surfaces (i.e. Root biomass). However, without evidence we do not know whether nutrient uptake by each seagrass shoot is dictated by the abundance of nutrients available to be absorbed, whether plants benefit from investing more in extracting nutrients from their immediate environment (e.g. High SRL) or the ability for roots to access new nutrient pools (e.g. Maximum root length) is the most important trait in the natural environment.

As nitrogen is hypothesised to be the main nutrient which limits growth at higher latitudes (Hemminga, 1998; Short, 1987), and sediment porewater ammonium the main nitrogen source, porewater ammonium was the focal nutrient of this study. Our aim was to quantify nitrogen uptake rates by several aquatic plant species from the sediment porewater environment. We hypothesised that species would have significantly different nutrient uptake rates, and these differences would be owing to the variation in morphological root traits between species. It would be highly difficult to conduct such an investigation in typical seagrass meadows because they are often monocultures (Hemminga and Duarte, 2000), which means that there would not likely be enough variability in uptake strategies to find 
insightful trends. In the northern Baltic Sea, the brackish-water conditions allow for a unique assembly of marine, estuarine and limnic species to coincide within the same meadow (Kautsky, 1988; Gustafsson and Norkko, 2016), therefore these communities were ideal for capturing a variety of uptake strategies facilitated by interspecific differences, while environmental conditions in the experiment remained relatively consistent. In this experiment, we examined how efficiently individual shoots could fulfil their nitrogen demand in response to a nutrient enrichment, and by comparing uptake rates between several species, we explored which uptake strategies were most beneficial to uptake rates. It is important to investigate which strategies enhance uptake in aquatic plants because it allows us to identify which mechanisms might otherwise be limiting nutrient uptake, thus nutrient cycling, in aquatic plant communities in the northern Baltic Sea.

\section{Methods}

\section{$\underline{\text { Study site and vegetation }}$}

The experiment was conducted in the shallow, submerged (2-4 m) mixed species vegetative communities around Tvärminne Zoological Station, Finland. Tvärminne is situated on the Hanko Peninsula of the Finnish archipelago, Baltic Sea $\left(59^{\circ} 50^{\prime} 400^{\prime \prime}\right.$ N, $23^{\circ} 14^{\prime} 56^{\prime \prime} \mathrm{E}$ WGS84). The species measured both have a limnic and marine origin; the freshwater species Ceratophyllum demersum, Myriophyllum spicatum, Stuckenia pectinata, Potamogeton perfoliatus and Zannichellia major, and the marine/brackish species Zostera marina and Ruppia cirrhosa. We incubated independent ramets of a clone to prevent translocation during incubation. Individuals with a single shoot were selected, however for small species with a trailing growth ( $R$. cirrhosa and Z. major), incubating multiple shoots was unavoidable. To prevent multiple species from being in the same incubation, we focussed on sparse stands. While sparse stands may not facilitate optimal conditions for aquatic plants, there is also less 
competition for nutrients and it is possible to investigate the nutrient uptake drivers of a single plant shoot without the influence of other shoots around. All incubations were at least $1 \mathrm{~m}$ apart from each other and individuals did not have noticeable grazer marks nor biofouling. Species-averaged canopy heights can range from 10-70 $\mathrm{cm}$ in this area and season (Gustafsson and Norkko, 2016), but individuals in this study did not exceed $20 \mathrm{~cm}$ in height. The sediment of the study site had approximately $0.5-0.8 \%$ OM content and 1.2-7.3 $\%$ silt fraction $(<0.063 \mathrm{~mm})$ (Gustafsson and Norkko, 2018).

Field work

Short term nutrient enrichment incubations were conducted in situ using SCUBA (Figure 1). ${ }^{15} \mathrm{~N}$ - enriched ammonium sulfate solution $(40 \mathrm{ml}, 47 \mu \mathrm{M}, 99$ at- $\%)$ was used as an immediate-release sediment fertiliser followed by incubations (Figure 1). 36 incubations were conducted on 4 days, 9 incubations on each day, during the late growth season (AugustSeptember) 2015 and 10 further incubations were conducted in September 2016 (Table 2). A minimum of 3 replicates of each species were incubated on each day and a further 3 specimens were collected intact from the surrounding meadow as ambient samples to obtain the background ${ }^{15} \mathrm{~N}$ in plant tissue. Not all incubations were successful due to insufficient root or belowground biomass available for the analysis, but this remained unknown until harvest (see Table 2). Rooting depths can vary between species (approx. 5-20 cm, pers. obs.) and within species (length can change by a magnitude of 10, Gustafsson and Norkko, 2018), which meant that selecting a standardised depth for enriching the sediment porewater and for measuring the ambient porewater nutrient availability to plants required due consideration. For instance, injecting the liquid fertiliser too shallow into the sediment would likely lead to an immediate re-release of the majority of fertiliser into the water column. Likewise, too deep an enrichment and the fertiliser would be out of reach of roots for some of the individuals. 
The sediment porewater was enriched at $7-8 \mathrm{~cm}$ deep; approximately half way down the depth of the core and close to the maximum lengths that the roots of aquatic plants in the study area typically reached (Gustafsson and Norkko, unpubl.). At this depth, it was predicted that the nutrients would reach the plants by diffusion and they would not be immediately diffused into the water column (Cheng et al., 2014, Chowdhury and Bakri, 2006; Clavero et al., 2000). The plants absorbed a fraction of the enriched source, meaning that there was enriched solution available for the plants throughout the experiment (Figure 1). Porewater samplers collected depth-integrated water samples in the upper $10 \mathrm{~cm}$ of sediment (see Gustafsson and Boström, 2011; Figure 1) to provide a best estimate of nutrient availability to plants in the region where roots were mostly found (pers. obs.) before the enrichment occurred. This data was used to estimate background porewater nutrient availability within the area which varied widely (Table 1).

Water column samples were periodically collected $(13 / 08 / 15 ; 10 / 09 / 15 ; 11 / 09 / 15$; 02/09/16) to estimate ammonium, nitrate, nitrite and phosphate availability to the aboveground parts of the aquatic plants (Table 1).

\section{$\underline{\text { Uptake metric calculations }}$}

The increase in nitrogen availability induced by the experimental enrichment was calculated as the percentage of nitrogen added compared to ambient $\mathrm{NH}_{4}{ }^{+}$concentrations, in moles, for each individual. Uptake by plants was calculated per unit nitrogen in order to detect the small-scale changes in nitrogen attributed to the short incubation time. The ability for plants to respond to the specific nutrient enrichment (response rates, $\mu \mathrm{gN} \mathrm{gN}^{-1} \mathrm{~h}^{-1}$, hereafter $\mathrm{RR}$ ) was determined using the equation:

$$
{ }^{15} \mathrm{~N} \text { (enriched plant) }-{ }^{15} \mathrm{~N} \text { (ambient plant) }
$$



species. Uptake rates which considered additional nutrient uptake by the ambient porewater nutrient pool (uptake rates, $\mu \mathrm{gN} \mathrm{gN}^{-1} \mathrm{~h}^{-1}$, hereafter UR) were calculated using mass-balanced isotope mixing equations (Collos, 1987) as described by Lepoint et al. (2002). The important difference between uptake response rate (RR) and uptake rate (UR) is that RR is a measurement of uptake of the enriched source, but UR incorporates ambient porewater ammonium measurements to estimate total ammonium uptake during the incubation. To avoid confusion, both units of uptake rate are named uptake metrics when they are being referred to collectively.

$\underline{\text { Statistical analysis }}$

Analyses were performed using the statistical software R (version 3.02.2, R Core Team 2015). For all analyses, the relevant assumptions relating to heteroscedasticity and the distribution of residuals were checked and in order to meet the criteria, some of the variables (RR, UR, porewater $\mathrm{NH}_{4}{ }^{+}$, total biomass, root biomass) were logarithmically transformed. concentrations were analysed using $95^{\text {th }}$ quantile regression. Quantile regression, such as $95^{\text {th }}$ quantile analysis, is an effective technique to explore the maximum (or factor ceiling) effect that a factor has on a dependent variable (Thomson et al., 1996; Thrush et al., 2003). 95 ${ }^{\text {th }}$ quantiles were calculated for 50mg biomass bins, which were then analysed using linear regression. Thus, statistical outputs represent trends of the boundary lines for the $95^{\text {th }}$ quantiles. One individual was removed from biomass-specific analyses because of its inordinately high biomass compared to the rest of the samples. The 2016 data was pooled with 2015 data for quantile regression analyses, but not for analyses which required species 
averages because only two species were incubated in 2016 and their pooled values may have led to misrepresentative differences between species.

A multiple-regression style General Linear Model (GLM) was used to analyse the effect of species identity, ambient porewater ammonium availability (log-transformed, hereafter $\mathrm{NH}_{4}{ }^{+}$) and their main effects on uptake metrics. For species comparisons, 3 replicates of each species were randomly selected from 2015 data for equal group sizes, however Ceratophyllum demersum was discounted because it did not have true roots and another species (Zannichellia major) was removed due to replicate loss.

Morphological characteristics of the experimental plants were not measured because it was important to process plant samples as quickly as possible after harvesting in order to prevent ${ }^{15} \mathrm{~N}$-loss from samples through leaching. Instead, the $95^{\text {th }}$ quantile regressions were used to infer which traits were likely to be important to enhance uptake rates, and pre-existing data was compared to uptake rates as a supportive tool for highlighting opportunities for future study. Species-averaged root traits were derived from a plant survey in the same study area at the same time of year, the previous year (Gustafsson and Norkko, 2018). These traits represented relative species differences in root traits for individuals growing in the study area (Table 3); from up to 5 quadrats per species, wherein up to 10 of the longest roots were measured. While rooting depth can vary between individuals, by using maximum root length the data represented the length that the roots of each species could typically extend to within the study area. Then, individual effects of $\mathrm{NH}_{4}{ }^{+}$and root biomass on uptake metrics were using up to three randomly selected uptake rates for each species. Z. major, which had been 
because it did not risk violation of the test assumptions and its presence did not change the significant outcome of the tests.

\section{$\underline{\text { Results }}$}

\section{Porewater nutrient availability}

Background porewater ammonium availability was highly variable within the replicates of individual plants (Table 1), which meant that when plants were experimentally enriched with identical doses of fertiliser the effect on porewater nutrient availability varied widely (approximately 2-74 \% $\mathrm{NH}_{4}{ }^{+}$enrichment, based on $20 \%$ sediment porosity measured at the site) and the starting nutrient conditions were not consistent between individuals. Such porewater variability had a significant, yet weak effect on uptake metrics (Table 4). Uptake response rates (RR) and uptake rates (UR) exhibited large variation too; ranging from -1.31 and $-30.15 \mu \mathrm{gN} \mathrm{gN}{ }^{-1} \mathrm{~h}^{-1}$ respectively, where uptake of the enriched source did not exceed the natural variability of ${ }^{15} \mathrm{~N}$, to 109.43 and $1032.25 \mu \mathrm{gN} \mathrm{gN}^{-1} \mathrm{~h}^{-1}$. It was highly unlikely that the nutrient enrichment produced toxic effects for the plants because the enrichment was minor in comparison to the variability of ambient nutrients in the sediment porewater.

\section{$\underline{\text { Biomass and nutrient cycling }}$}

There were no trends between root biomass and uptake metrics (Table 4), however total biomass was significantly linked to the upper limits of all the nutrient cycling metrics that were measured in this study. For instance, there were significant logarithmic declines in the $95^{\text {th }}$ percentiles of uptake metrics (UR \& RR) as biomass increased (Figure $2 \mathrm{~A} \& \mathrm{~B}$, Table 5), and larger individuals were more likely to be limited in their overall uptake rate (UR) rather than their capacity to respond to the experimental enrichment (RR, Figure $2 \mathrm{~A} \& \mathrm{~B}$, Table 5). Similarly, the sediment porewater surrounding larger plants was significantly less likely to be $\mathrm{NH}_{4}{ }^{+}$replete (Figure 2C, Table 5) and leaf tissue nitrogen concentrations of larger plants did 
not reach the same maximum concentrations as for smaller plants; a trend which was not

262 singly controlled by species identity (Figure 2D).

\section{$263 \quad$ Root traits and uptake rates}

264 Species did not have significantly different uptake rates (UR) nor response rates (RR) ( $t_{17}$, $26514=.654, p>.05 ; \mathrm{t} 17,14=.765, p>.05$, respectively), nor did species identity interact with 266 porewater ammonium availability to produce significantly different URs and RRs $\left(\mathrm{t}_{17,14}=-\right.$ $267.998, p>.05 ; \mathrm{t} 17,14=-.881, p>.05)$. Supportive analyses which refer to an external trait 268 dataset suggest that while there may not have been species differences, species traits could 269 provide insights into the drivers of uptake rates. For instance, species capable of growing longer roots (Mean Max Root Length, MMRL) were significantly more adept at responding

271 to the experimental nutrient pulse by rank (RR; Figure 3A, Table 4) but MMRL was not

272 significantly beneficial for the rank order of overall uptake rates (UR; Figure 3B, Table 4).

273 There were no significant relationships between Specific Root Lengths (SRL) and the ranks of uptake metrics (UR \& RR, Table 4). 
This study has provided novel insights into the short-term dynamics of nutrient uptake by aquatic plants, not only for plants in the northern Baltic Sea but also for vascular plants in other submerged aquatic ecosystems. Overall, results showed that the nutrient demands of the plants significantly affected uptake rates, nutrient storage in plant tissue and the nutrient availability in the sediment porewater (Figure 2, Figure 4). Therefore, short-term nutrient uptake in these aquatic plant meadows was likely to be largely driven by the presence and characteristics of the aquatic plants, more so than by environmental nutrient availability. For example, as plants increased in size, their ability to cycle nutrients to their full potential was significantly hindered and the nutrient availability in the sediment porewater was likewise depleted (Figure 2). This suggests that access to new nutrient sources is likely to benefit nutrient uptake and nutrient cycling by plants. Such conclusions are likewise suggested by supportive analyses which identify a potential link between maximum root lengths and uptake rates (Table 4). These insights are informative and beneficial because they described the challenges for nutrient uptake experienced by a single aquatic plant shoot, and findings parameterise the unfulfilled potential for some aquatic plants to cycle nutrients more efficiently.

\section{The biomass paradox}

Unlike other characteristics of a plant, such as root length and thickness, biomass does not only represent the capacity for plants to acquire nitrogen (e.g. Tessier and Raynal, 2003) but it also represents their nitrogen demand (Poorter and Nagel, 2000). As an individual increases in size, the amount of nitrogen it needs to maintain the same nutrient concentrations in its more abundant tissues becomes exponentially higher (Figure 2, Blackman, 1919). While the overall nitrogen uptake rates of the plants in this study were likely to be higher as plants increased in biomass (hereafter 'larger plants') their capacity to meet their increased demand 
was significantly limited (Figure 2A \& B). Thus, the increased capacity to absorb nitrogen that a larger biomass might provide, such as by having more absorptive surfaces (Blackman, 1919), was outweighed by the increased demand from having larger standing nitrogen stocks (Figure 2). Also, larger plants were less likely to store the same standing nitrogen stocks $(\% \mathrm{DW})$ as smaller plants (Figure 2D), suggesting that larger plants may not be absorbing nitrogen to their full potential. This is a new insight into the efficiency of nutrient cycling by aquatic plants. In addition, the porewater nitrogen was more likely to be depleted in the vicinity of larger plants (Figure 2C). All trends were highly variable for plants with a smaller biomass, which made factor ceiling analysis a highly valuable tool. Its results suggest that firstly, demand was represented more strongly than supply in biomass-uptake relationships (Figure 2A \& B), secondly the larger plants did not store N (\%DW) standing stocks as high as smaller plants, which was not necessarily related to species (Figure 2D) and lastly an individual plant can deplete porewater $\mathrm{NH}_{4}{ }^{+}$(Figure 2C). Due to the aforementioned nutrient uptake (e.g. Göransson and Eldhuset, 1991) and the threshold N (\%DW) concentration above which further uptake becomes luxurious is unknown. Nevertheless, larger plants were likely to not have been cycling nitrogen to their fullest potential and even during nitrogen uptake should be re-evaluated. et al., 1992); that with increasing nutrient availability in the water column, the light availability decreases as responsive phytoplankton blooms attenuate the light which is 
transmitted to the plants from the surface. But results from this study exhibited an additional nitrogen compromise for plants that might not be expected in a eutrophicated sea (Gustafsson et al., 2012). Ammonium concentrations in the sediment porewater were lower than the global median for aquatic plants meadows (Hemminga, 1998). Trends showed that overall, the more investment in biomass the less capable plants were at meeting their nutrient demands (Figure 2D), which has been previously unobserved in the field. These trends between aquatic plant biomass and tissue nitrogen concentrations represented not only the ability for plants to absorb their nutrients from the sediment, but also the water column, and the trade-off between investing in belowground and aboveground biomass for uptake is also accounted for. Therefore, these interpretations apply to the capacity for a whole plant to meet its nutrient demands. It is noteworthy that this experiment was conducted at the peak for plant biomass, but not for production, and so if the experiment was conducted at the peak of productivity the biomass-uptake trends observed could become even more accentuated. Overall, these findings show that larger aquatic plants are not cycling nutrients to their full potential. Thus, they could potentially become more efficient at their role in the coastal nutrient filter if circumstances allowed it. Strategies, such as morphological root traits, could thus be highly valuable for helping plants to cycle nutrients more effectively. For instance, depending on the extent of nutrient variability, the ability for plants to absorb nutrients in the vicinity (i.e. Root biomass, Specific Root Length) or to access new nutrient pools (i.e. Maximum root length) could be highly valuable for enhancing nutrient uptake.

$\underline{\text { Root traits and uptake rates }}$

In general, an increase in ambient nutrient availability leads to an accelerating increase in the rate of nutrient uptake by an individual, typically described by a hyperbolic trend (Caassen and Barber, 1976). However, such a trend was not detected in this experiment. Porewater estimates may not have been representative of the relative availability of nutrients in the 
depletion zones, or an interaction with other factors that were more influential drivers of uptake rate (e.g. Plant traits, plant biomass, Figure 4) could have convoluted the conventional porewater nutrient-uptake trend. This was likewise the case for root biomass (Table 4), because root biomass represents a dynamic equilibrium between environmental nutrient availability and plant nutrient demands, making it highly unlikely that a direct relationship could be observed between root biomass and any plant nutrient parameters (e.g. Ruffel et al., 2011; Figure 4). Given that the uptake rates, plant stores and sediment supply of nutrients were largely influenced by the plant biomass in this study, the nutrient dynamics were likely to be largely plant-driven. These findings suggest that access to new nutrient sources would enhance uptake rates and plant stores. Similarly, when uptake rates were compared to preexisting trait data, species with the potential to grow longer roots appeared to be more equipped to respond to the nutrient source (Figure 2). This seemed less beneficial when the effect of porewater availability was also taken into account to estimate overall uptake rates (Figure 2). Thus, the plants would potentially benefit from longer roots to respond to the nutrient enrichment, but because longer roots cannot guarantee a proportional increase in access to more nutrients it does not necessarily mean that the overall uptake rate would be faster. Within the zone from which plants can deplete nutrients, it is unlikely that properties that increase the absorptive properties of the roots would be as helpful as accessing new zones with nutrient sources. Otherwise, one would expect that porewater nutrient availability or root biomass would have had stronger roles in the different uptake rates of individuals of this study (Figure 2; Figure 4). Instead, the plant biomass (i.e. Demand) had the prevailing influence (Figure 2). Supporting this result, specific root length was not significantly linked to the rank order of uptake rates in the supportive analyses. It is unlikely that variability of further physiological strategies for absorption would significantly affect uptake rates. 
to a nutrient source is more important than variability for plants to retrieve the nitrogen once it had been accessed. Other traits which might enhance access to nutrient sources include expanding the spatial reach for nutrients than seeking nutrients within a smaller zone, based on terrestrial examples (see Kembel et al., 2008; Campbell et al., 1991 and references within), which could include growing multiple ramets because labour is divided between ramets, simultaneously increasing the reach (Roiloa and Hutchings, 2013).

\section{$\underline{\text { Conclusion }}$}

To our knowledge, this is the first study to measure the nitrogen uptake of a variety of different aquatic species in relatively similar environmental conditions in the field. Furthermore, the influence of different plant characteristics was surveyed in a natural environment while other factors remained relatively similar. Results show a previously unidentified, extreme spatial variability of sediment porewater ammonium availability within an aquatic plant meadow, and its variability is reflected by the uptake strategies, challenges and successes for even a single aquatic plant shoot. Overall, our results suggest that the larger plants could perform better at their role as nutrient filters in the coastal zone, and increasing access to new nutrient sources could help plants to uptake and store nutrients more effectively. Thus, larger plants have the potential to cycle nutrients more effectively, and this could potentially be facilitated by increasing the access to new nutrient pools which would benefit from nutrient cycling by aquatic plants. These findings fill a knowledge gap because such conditions for aquatic plants in their natural settings were previously unknown. Future studies which investigate the mechanisms that increase root access to new nutrient sources could help to understand how nutrient cycling by aquatic plants might be enhanced. For example, more diverse aquatic meadows may enhance resource partitioning (Gustafsson and Boström, 2011) and thus nutrients may be cycled more effectively, and nutrient cycling by fauna can increase plant growth (Peterson and Heck, 2001; Peterson and Heck, 1999). To 
follow from this study, there is an opportunity to investigate how community composition (Gustafsson and Boström, 2011), the activity of infauna (e.g. Villnäs et al., 2018) and other factors increase the connectivity of aquatic plant nutrient depletion zones to areas which would benefit from their role as nutrient filters. Ultimately, such studies may help to develop effective conservation strategies to mitigate eutrophication by providing the most effective solutions to enhance the role of aquatic plant meadows as nutrient filters.

\section{$\underline{\text { Acknowledgements }}$}

We would like to thank Hanna Halonen; research technician, and volunteers Mari Vanharanta, Ella Pippingsköld and Pauliina Saarman for assistance in the field. Thanks also to Iván Rodil and Anna Villnäs for their analytical and literary advice during the preparation of the manuscript. This work was funded by the Walter and Andrée de Nottbeck Foundation (CA), Academy of Finland (CG, grant number 295443; AN, grant number 294853) and Svenska kulturfonden (CG) and conducted at Tvärminne Zoological Station, University of Helsinki.

\section{$\underline{\text { Literature cited }}$}

Aerts, R., 1999. Interspecific competition in natural plant communities: Mechanisms, tradeoffs and plant-soil feedbacks. Journal of Experimental Botany, 50(330), pp. 29-37.

Andersen, J.H., Laamamen, M., Aigars, J., Axe, P., Blomqvist, M., Carstensen, J., Claussen, U., Josefson, A.B., Flemming-Lehtinen, V. and Järvinen, M., 2009. Eutrophication in the Baltic Sea - An integrated thematic assessment of the effects of nutrient enrichment in the Baltic Sea region.

Armitage, A.R., Frankovich, T.A. and Fourqurean, J.W., 2011. Long-term effects of adding nutrients to an oligotrophic coastal environment. Ecosystems, 14(3), pp. 430-444.

Blackman, V., 1919. The compound interest law and plant growth. Annals of Botany, 33(131), pp. 353-360. 
Caassen, N. and Barber, S., 1976. Simulation model for nutrient uptake from soil by a growing plant root system. Agronomy Journal, 68(6), pp. 961-964.

Campbell, B., Grime, J. and Mackey, J., 1991. A trade-off between scale and precision in resource foraging. Oecologia, 87(4), pp. 532-538.

Campbell, J.E. and Fourqurean, J.W., 2014. Ocean acidification outweighs nutrient effects in structuring seagrass epiphyte communities. Journal of Ecology, 102(3), pp. 730-737.

Cheng, X., Zeng, Y., Guo, Z. and Zhu, L., 2014. Diffusion of nitrogen and phosphorus across the sediment-water interface and in seawater at aquaculture areas of Daya Bay, China. International Journal of Environmental Research and Public Health, 11(2), pp. 1557-1572.

Chowdhury, M. and Bakri, D.A., 2006. Diffusive nutrient flux at the sediment-water interface in Suma Park Reservoir, Australia. Hydrological Sciences Journal, 51(1), pp. 144156.

Clavero, V., Izquierdo, J., Fernandez, J. and Niell, F., 2000. Seasonal fluxes of phosphate and ammonium across the sediment-water interface in a shallow small estuary (Palmones River, southern Spain). Marine Ecology Progress Series, pp. 51-60.

Collos, Y., 1987. Calculations of $15 \mathrm{~N}$ uptake rates by phytoplankton assimilating one or several nitrogen sources. International Journal of Radiation Applications and Instrumentation. Part A. Applied Radiation and Isotopes, 38(4), pp. 275-282.

Comas, L. and Eissenstat, D., 2004. Linking fine root traits to maximum potential growth rate among 11 mature temperate tree species. Functional Ecology, 18(3), pp. 388-397.

De Kroon, H. and Mommer, L., 2006. Root foraging theory put to the test. Trends in Ecology \& Evolution, 21(3), pp. 113-116.

Erftemeijer, P.L. and Middelburg, J.J., 1995. Mass balance constraints on nutrient cycling in tropical seagrass beds. Aquatic Botany, 50(1), pp. 21-36.

Evrard, V., Kiswara, W., Bouma, T.J. and Middelburg, J.J., 2005. Nutrient dynamics of seagrass ecosystems: $15 \mathrm{~N}$ evidence for the importance of particulate organic matter and root systems. Marine Ecology Progress Series, 295, pp. 49-55.

Ferdie, M. and Fourqurean, J.W., 2004. Responses of seagrass communities to fertilization along a gradient of relative availability of nitrogen and phosphorus in a carbonate environment. Limnology and Oceanography, 49(6), pp. 2082-2094.

Fourqurean, J.W., Zieman, J.C. and Powell, G.V.N., 1992. Relationships between Porewater Nutrients and Seagrasses in a Subtropical Carbonate Environment. Marine Biology, 114(1), pp. 57-65.

Furman, B.T., Jackson, L.J. and Peterson, B.J., 2017. Edaphic resource foraging by Zostera marina (Linnaeus) patches. Journal of Experimental Marine Biology and Ecology, 486, pp. 214-221. 
Göransson, A. and Eldhuset, T.D., 1991. Effects of aluminium on growth and nutrient uptake of small Picea abies and Pinus sylvestris plants. Trees-Structure and Function, 5(3), pp. 136142.

Gustafsson, B.G., Schenk, F., Blenckner, T., Eilola, K., Meier, H.M., Müller-Karulis, B., Neumann, T., Ruoho-airola, T., Savchuk, O.P. and Zorita, E., 2012. Reconstructing the development of Baltic Sea eutrophication 1850-2006. Ambio, 41(6), pp. 534-548.

Gustafsson, C. and Norkko. A, 2018. Quantifying the importance of functional traits for primary production in aquatic plant communities. Journal of Ecology, 00, pp. 1-13.

Gustafsson, C. and Norkko, A., 2016. Not all plants are the same: Exploring metabolism and nitrogen fluxes in a benthic community composed of different aquatic plant species. Limnology and Oceanography, 61(5), pp. 1787-1799.

Gustafsson, C. and Boström, C., 2011. Biodiversity influences ecosystem functioning in aquatic angiosperm communities. Oikos, 120(7), pp. 1037-1046.

Hemminga, M.A., 1998. The root/rhizome system of seagrasses: an asset and a burden. Journal of Sea Research, 39(3-4), pp. 183-196.

Hemminga, M.A. and Duarte, C.M., 2000. Seagrass Ecology. Cambridge University Press.

Kautsky, L., 1988. Life strategies of aquatic soft bottom macrophytes. Oikos, pp. 126-135.

Kembel, S.W., De Kroon, H., Cahill JR, J.F. and Mommer, L., 2008. Improving the scale and precision of hypotheses to explain root foraging ability. Annals of Botany, 101(9), pp. 12951301.

Kennedy, H., Beggins, J., Duarte, C.M., Fourqurean, J.W., Holmer, M., Marbà, N. and Middelburg, J.J., 2010. Seagrass sediments as a global carbon sink: Isotopic constraints. Global Biogeochemical Cycles, 24, pp. GB4026-GB4026.

Kenworthy, J.W. and Thayer, G.W., 1984. Production and decomposition of the roots and rhizomes of seagrasses, Zostera marina and Thalassia testudinum, in temperate and subtropical marine ecosystems. Bulletin of Marine Science, 35(3), pp. 364-379.

Lepoint, G., Millet, S., Dauby, P., Gobert, S. and Bouquegneau, J., 2002. Annual nitrogen budget of the seagrass Posidonia oceanica as determined by in situ uptake experiments. Marine Ecology Progress Series, 237, pp. 87-96.

Marbà, N., Hemminga, M.A., Mateo, M.A., Duarte, C.M., Mass, Y.E., Terrados, J. and Gacia, E., 2002. Carbon and nitrogen translocation between seagrass ramets. Marine Ecology Progress Series, 226, pp. 287-300.

McGlathery, K.J., Sundbäck, K. and Anderson, I.C., 2007. Eutrophication in shallow coastal bays and lagoons: the role of plants in the coastal filter. Marine Ecology Progress Series, 348, pp. 1-18. 
Mutchler, T. and Hoffman, D.K., 2017. Response of seagrass (Thalassia testudinum) metrics to short-term nutrient enrichment and grazing manipulations. Journal of Experimental Marine Biology and Ecology, 486, pp. 105-113.

Olsen, Y.S. and Valiela, I., 2010. Effect of Sediment Nutrient Enrichment and Grazing on Turtle Grass Thalassia testudinum in Jobos Bay, Puerto Rico. Estuaries and Coasts, 33(3), pp. 769-783.

Pérez, M., Romero, J., Duarte, C.M. and Sand-Jensen, K., 1991. Phosphorus limitation of Cymodocea nodosa growth. Marine Biology, 109(1), pp. 129-133.

Peterson, B.J. and Heck JR, K.L., 2001. An experimental test of the mechanism by which suspension feeding bivalves elevate seagrass productivity. Marine Ecology Progress Series, 218, pp. 115-125.

Peterson, B.J. and Heck, K.L., 1999. The potential for suspension feeding bivalves to increase seagrass productivity. Journal of Experimental Marine Biology and Ecology, 240(1), pp. 37-52.

Poorter, H. and Remkes, C., 1990. Leaf-Area Ratio and Net Assimilation Rate of 24 WildSpecies Differing in Relative Growth-Rate. Oecologia, 83(4), pp. 553-559.

Roiloa, S.R. and Hutchings, M.J., 2013. The effects of physiological integration on biomass partitioning in plant modules: an experimental study with the stoloniferous herb Glechoma hederacea. Plant Ecology, 214(4), pp. 521-530.

Ruffel, S., Krouk, G., Ristova, D., Shasha, D., Birnbaum, K.D. and Coruzzi, G.M., 2011. Nitrogen economics of root foraging: transitive closure of the nitrate-cytokinin relay and distinct systemic signaling for $\mathrm{N}$ supply vs. demand. Proceedings of the National Academy of Sciences of the United States of America, 108(45), pp. 18524-18529.

Short, F.T., 1987. Effects of Sediment Nutrients on Seagrasses - Literature-Review and Mesocosm Experiment. Aquatic Botany, 27(1), pp. 41-57.

Tessier, J.T. and Raynal, D.J., 2003. Use of nitrogen to phosphorus ratios in plant tissue as an indicator of nutrient limitation and nitrogen saturation. Journal of Applied Ecology, 40(3), pp. 523-534.

Thomson, J.D., Weiblen, G., Thomson, B.A., Alfaro, S. and Legendre, P., 1996. Untangling multiple factors in spatial distributions: lilies, gophers, and rocks. Ecology, 77(6), pp. 16981715.

Thrush, S.F., Hewitt, J.E., Norkko, A., Nicholls, P.E., Funnell, G.A. and Ellis, J.I., 2003. Habitat change in estuaries: predicting broad-scale responses of intertidal macrofauna to sediment mud content. Marine Ecology Progress Series, 263, pp. 101-112.

Touchette, B.W. and Burkholder, J.M., 2000. Review of nitrogen and phosphorus metabolism in seagrasses. Journal of Experimental Marine Biology and Ecology, 250(1-2), pp. 133-167. 
532 Villnäs, A., Hewitt, J., Snickars, M., Westerbom, M. and Norkko, A., 2018. Template for 533 using biological trait groupings when exploring large-scale variation in seafloor

534 multifunctionality. Ecological Applications, 28(1), pp. 78-94.

535 Wirachwong, P. and Holmer, M., 2010. Nutrient dynamics in 3 morphological different 536 tropical seagrasses and their sediments. Aquatic Botany, 93(3), pp. 170-178.

537

$538 \underline{\text { Tables }}$

539

Table 1. Overall mean, standard deviation (SD) and frequency (n) of ammonium $\left(\mathrm{NH}_{4}^{+}\right)$, nitrate and nitrite $\left(\mathrm{NO}_{2}{ }^{-}+\mathrm{NO}_{3}{ }^{-}\right)$and phosphate $\left(\mathrm{PO}_{4}{ }^{3-}\right)$ concentrations $\left(\mu \mathrm{g} \mathrm{L}^{-1}\right)$ in the sediment porewater next to individual plants and the water column.

\begin{tabular}{l|l|l|l|}
\hline & Mean & \multicolumn{1}{l}{$\mathrm{SD}$} & $\mathrm{N}$ \\
\hline Porewater & & & \\
\hline $\mathrm{NH}_{4}{ }^{+}$ & 21.63 & 13.12 & 58 \\
\hline $\mathrm{NO}_{2}{ }^{-}+\mathrm{NO}_{3}{ }^{-}$ & 1.98 & 2.75 & 11 \\
\hline $\mathrm{PO}_{4}{ }^{3-}$ & 3.44 & 2.76 & 11 \\
\hline Water column & & & \\
\hline $\mathrm{NH}_{4}{ }^{+}$ & 0.10 & 0.03 & 6 \\
\hline $\mathrm{NO}_{2}{ }^{-}+\mathrm{NO}_{3}{ }^{-}$ & 0.14 & & 2 \\
\hline $\mathrm{PO}_{4}{ }^{-}$ & 0.13 & 0.04 & 3 \\
\hline
\end{tabular}

Table 2. Details of enrichment events including dates, which species were enriched (Treatment), number of successful replicates for each species (originally 3 replicates per species per day in 2015. No replicates lost in 2016), average temperature $\left({ }^{\circ} \mathrm{C}\right)$ and photosynthetically active radiation (PAR; $\mathrm{mol} \mathrm{m}^{-2} \mathrm{~h}^{-1}$; HOBO Pendant ${ }^{\circledR}$ Temperature/Light Data Logger $64 \mathrm{~K}$, Onset, USA, light data converted to PAR as described by Gustafsson, Norkko 2016) during each incubations.

\begin{tabular}{lccccc}
\hline Enrichment & Date & Treatment & Successful replicates & Temp. ${ }^{\circ} \mathrm{C}$ & PAR $\left(\mathrm{mol} \mathrm{m}^{-2} \mathrm{~h}^{-1}\right)$ \\
\hline 1 & 13.08 .15 & Cerdem, Rupcir, Zanmaj & $3,3,2$ & 16 & 1.2 \\
2 & 26.08 .15 & Potperf, Zosmar & 3,3 & 17 & 1.2 \\
3 & 27.08 .15 & Myrspi, Stupec & 2,1 & 18 & 0.9 \\
4 & 10.09 .15 & Myrspi, Potper & 1,1 & 19 & 0.7 \\
5 & 11.09 .15 & Myrspi, Potper, Stupec & $3,1,3$ & 19 & 0.6 \\
6 & 02.09 .16 & Myrspi, Potper & 7,3 & 16 & 1.1 \\
\hline
\end{tabular}


Table 3. Mean Max Root Length (mm) and Specific Root Length means ( \pm Standard Error, SE) of study species in the same area of the experiment. Data source Gustafsson \& Norkko (2018).

\begin{tabular}{l|c|c|}
\hline Species & MMRL (mm) & SRL \\
\hline Myriophyllum spicatum & $9.8 \pm 1.3$ & $5.7 \pm 1.6$ \\
\hline Potamogeton perfoliatus & $7.4 \pm 0.4$ & $14.0 \pm 1.2$ \\
\hline Ruppia cirrhosa & $8.7 \pm 1.2$ & $11.6 \pm 1.3$ \\
\hline Stuckenia pectinata & $6.4 \pm 1.2$ & $19.5 \pm 2.0$ \\
\hline Zannichellia major & $7.5 \pm 1.4$ & $11.2 \pm 0.6$ \\
\hline Zostera marina & $6.4 \pm 0.8$ & $8.5 \pm 0.7$ \\
\hline
\end{tabular}

Table 4. Regression statistics for aquatic plant uptake rate (UR, $\mu \mathrm{gN} \mathrm{gN}^{-1} \mathrm{~h}^{-1}$ ) and uptake response rate ( $\mathrm{RR}, \mu \mathrm{g}^{15} \mathrm{~N} \mathrm{gN}^{-1} \mathrm{~h}^{-1}$ ), in response to changes in porewater ammonium availability $\left(\mathrm{NH}_{4}^{+}, \mu \mathrm{M}\right)$ and root biomass (mg). Rank regression statistics for UR and RR with changes in species-averaged Mean Max Root Length (MMRL, mm) and species-averaged specific root length (SRL).

\begin{tabular}{|c|c|c|c|c|c|c|}
\hline & \multirow[b]{2}{*}{ Coefficient } & \multirow[b]{2}{*}{ Intercept } & \multicolumn{4}{|c|}{ Regression statistics } \\
\hline & & & $r^{2}$ & $n$ & $F$ & $P$ \\
\hline \multicolumn{7}{|c|}{ Porewater $\left[\mathrm{NH}_{4}{ }^{+}\right]$} \\
\hline UR & .9112 & 3.5734 & .2902 & 30 & 11.45 & .002 \\
\hline $\mathrm{RR}$ & .2556 & 2.3424 & .0694 & 30 & 2.088 & .160 \\
\hline \multicolumn{7}{|c|}{ Root biomass (mg) } \\
\hline UR & -.007912 & 6.185049 & .02568 & 17 & .3954 & .539 \\
\hline \multirow[t]{3}{*}{ RR } & -.002668 & 2.204714 & .002517 & 23 & .05299 & .820 \\
\hline & & & \multicolumn{4}{|c|}{ Rank regression statistics } \\
\hline & Coefficient & Intercept & $n$ & Over: & d test & $P$ \\
\hline \multicolumn{7}{|c|}{ Mean max root length } \\
\hline UR & 262.63 & -1570.02 & 6 & 3.572 & & .053 \\
\hline $\mathrm{RR}$ & 4.0781 & -21.4567 & 6 & 4.273 & & .034 \\
\hline \multicolumn{7}{|c|}{ Specific root length } \\
\hline UR & -.69579 & 18.2358 & 6 & 1.320 & & .296 \\
\hline $\mathrm{RR}$ & -29.799 & 657.346 & 6 & 0.671 & & .526 \\
\hline
\end{tabular}


Table 5. $95^{\text {th }}$ quantile regression statistics for aquatic plant uptake rate ( $\ln (\mathrm{UR}), \mu \mathrm{gN} \mathrm{gN}^{-1}$

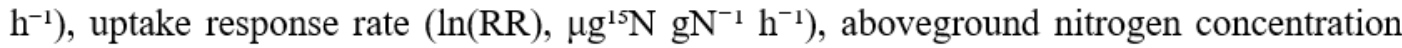
(AG N, \%DW) and porewater ammonium availability $\left(\mathrm{NH}_{4}{ }^{+}, \mu \mathrm{M}\right)$ when compared to total biomass (ln(biomass), $\mathrm{mg}$ ) of an individual plant.

\begin{tabular}{|c|c|c|c|c|c|c|}
\hline & \multirow[b]{2}{*}{ Coefficient } & \multirow[b]{2}{*}{ Intercept } & \multicolumn{4}{|c|}{$95^{\text {th }}$ quantile regression statistics } \\
\hline & & & $r^{2}$ & $N$ & $F$ & $P$ \\
\hline \multicolumn{7}{|l|}{ Total biomass } \\
\hline UR & -2.1609 & 18.0999 & 0.774 & 12 & 38.67 & $<.0001$ \\
\hline $\mathrm{RR}$ & -1.5419 & 11.1518 & 0.7212 & 12 & 29.46 & $<.0001$ \\
\hline AG N (\%DW) & -0.8825 & 7.3764 & 0.7969 & 15 & 55.92 & $<.0001$ \\
\hline Porewater $\mathrm{NH}_{4}{ }^{+}$ & -12.380 & 93.398 & 0.5943 & 12 & 17.11 & .002 \\
\hline
\end{tabular}

$545 \quad$ Figure legends

546 Figure 1. Experimental design of an incubation for a single aquatic plant. Multiple incubations (min.

547 batch of 9) were conducted simultaneously within an incubation day.

548 Figure 2. Total plant biomass (ln(biomass), mg dry weight (DWT)) and, A: Uptake rates (ln (UR), $\left.549 \mu \mathrm{gN} \mathrm{gN}^{-1} \mathrm{~h}^{-1}\right), \mathrm{B}$ : Uptake response rates (ln (RR), $\left.\mu \mathrm{gN} \mathrm{gN}^{-1} \mathrm{~h}^{-1}\right), \mathrm{C}$ : Porewater ammonium $\left(\mathrm{NH}_{4}^{+}\right.$, $550 \mu \mathrm{M}$ ) and D: Aboveground nitrogen concentration (AG N, percentage dry weight; \%DW). 'D' displays 551 data for enriched and non-enriched plants. Dotted lines denote $95^{\text {th }}$ percentiles. $95^{\text {th }}$ percentiles were 552 calculated before the data was logarithmically transformed; two values are missing from A and B due 553 to disproportionately negative values.

555 Figure 3. Species-averaged mean max root lengths $(\mathrm{mm})$ and $(\mathrm{A})$ uptake response rates $(\ln (\mathrm{RR}+10))$,

556 (B) species-averaged uptake rates $(\ln (\mathrm{UR}+100)),\left(\mu \mathrm{gNgN}^{-1} \mathrm{~h}^{-1}\right)$.

558 Figure 4. Conceptual diagram of the trade-offs occurring in nutrient uptake for aquatic plants in the 559 northern Baltic Sea, based on current evidence from this study and published literature. Solid lines: 
560 Evidence-based trends considering interspecific and intraspecific trends. Dashed line: May not apply

561 to a single shoot of a plant that has multiple ramets (Roiloa, Hutchings 2013). Reverse trend for plants

562 with multiple ramets. ${ }^{a}=$ Marba et al. 2002, while other components to the model were inferred from

563 the results of this study.
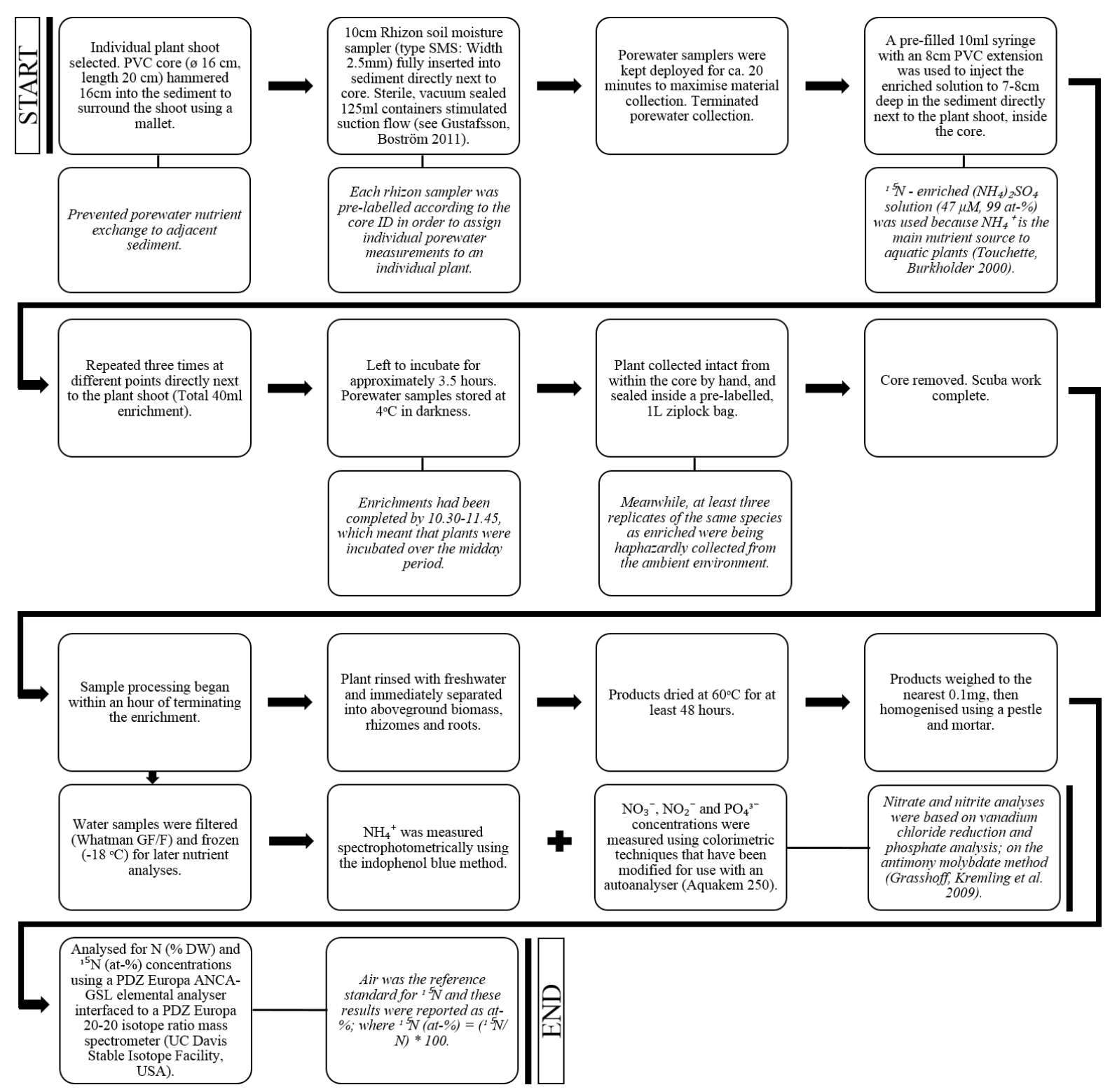

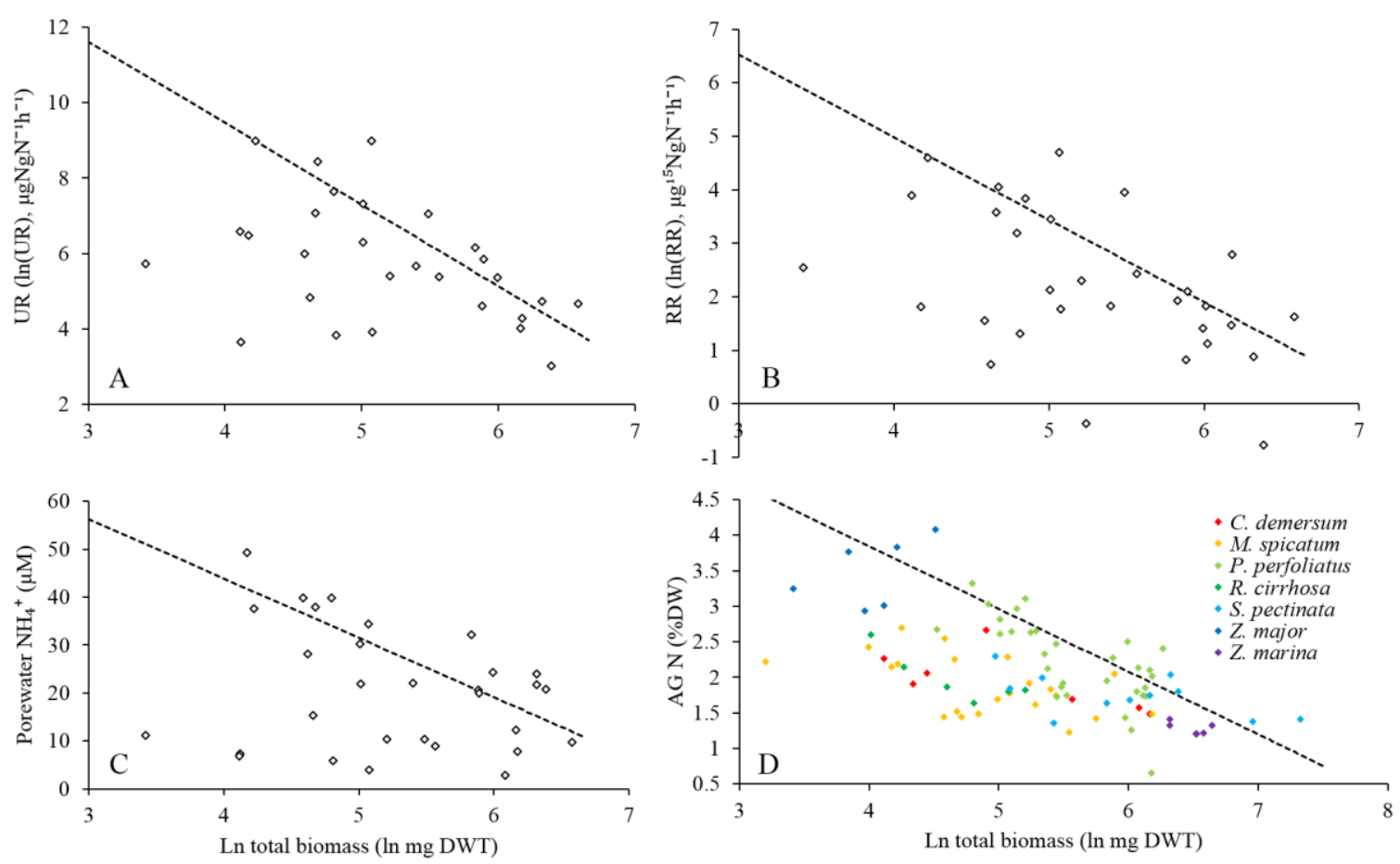

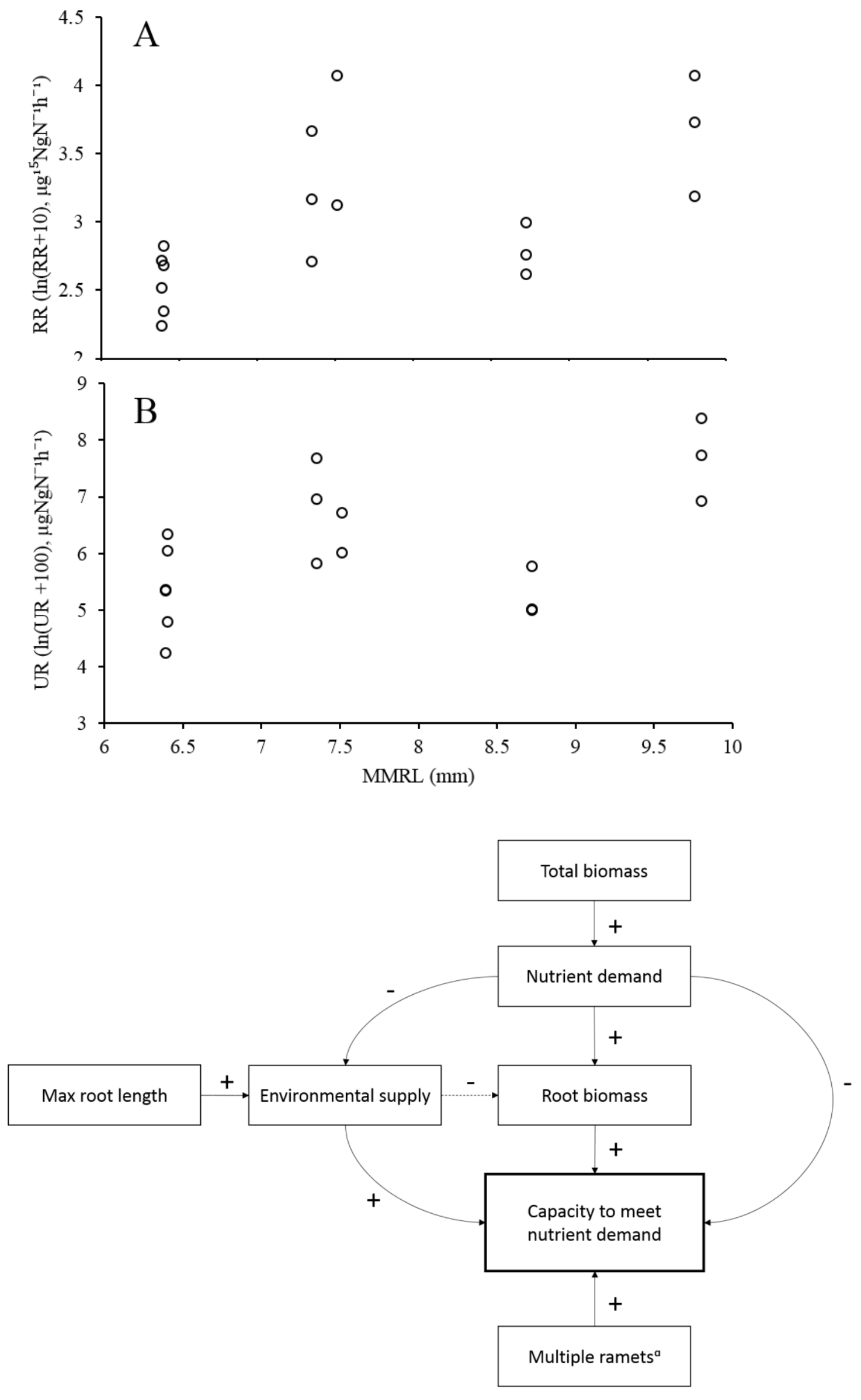